\title{
WHAT CAUSED THE BIG BANG?
}




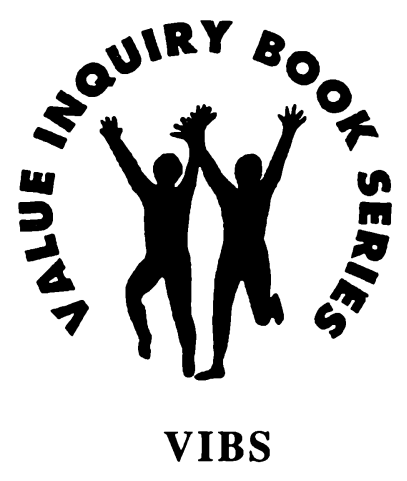

Volume 115

\section{Robert Ginsberg Executive Editor}

G. John M. Abbarno

Associate Editors

Mary-Rose Barral

Gerhold K. Becker

Kenneth A. Bryson

C. Stephen Byrum

H. G. Callaway

Rem B. Edwards

Robert N. Fisher

William C. Gay

Dane R. Gordon

J. Everet Green

Heta Aleksandra Gylling

Matti Häyry

Steven V. Hicks

Richard T. Hull

Laura Duhan Kaplan

Joseph C. Kunkel

Vincent L. Luizzi

Alan Milchman

George David Miller

Jon Mills

Peter A. Redpath

Alan Rosenberg

Arleen L. F. Salles

John R. Shook

Alan Soble

Anne Waters

John R. Welch

A volume in

Philosophy and Religion (PAR)

Kenneth A. Bryson, Editor 


\title{
WHAT CAUSED THE BIG BANG?
}

\author{
Rem B. Edwards
}

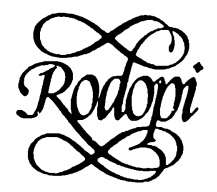

Amsterdam - New York, NY 2001 
This is an open access title distributed under the terms of the CC BYNC-ND 4.0 license, which permits any non-commercial use, distribution, and reproduction in any medium, provided no alterations are made and the original author(s) and source are credited. Further information and the complete license text can be found at https://creativecommons.org/ licenses/by-nc-nd/4.0/

The terms of the CC license apply only to the original material. The use of material from other sources (indicated by a reference) such as diagrams, illustrations, photos and text samples may require further permission from the respective copyright holder.

The paper on which this book is printed meets the requirements of "ISO 9706:1994, Information and documentation - Paper for documents Requirements for permanence".

ISSN: 0929-8436

ISBN (paperback): 978-90-420-1407-7

E-ISBN: 978-90-04-49603-3

Copyright 2021 by Rem B. Edwards. Published by Koninklijke Brill NV, Leiden, The Netherlands.

Koninklijke Brill NV incorporates the imprints Brill, Brill Nijhoff, Brill Hotei, Brill Schöningh, Brill Fink, Brill mentis, Vandenhoeck \& Ruprecht, Böhlau Verlag and V\&R Unipress. 
In memory of Curry T. Haynes

Professor of Biology, Emory at Oxford,

Who helped me to understand and love living things 
Rem B. Edwards - 9789004496033

Downloaded from Brill.come4/26/2023 10:34:58AM via free access 


\section{CONTENTS}

Editorial Foreword

xiii

Kenneth A. Bryson

Preface

XV

Acknowledgments

xxi

ONE Scientific Cosmology and the Big Bang 1

1.The Evolution of the Universe 3

A. The Initial Singularity 3

B. Planck Time and Space 4

C. Inflation 5

D. Evolution of Physical Forces, Particles, and the Laws of Nature 7

E. From a Universe of Radiation to a Gaseous Universe 9

F. Creation of Quasars, Galaxies, Stars, Solar Systems, Heavier Elements 10

G. Formation of Our Sun, Its Planets, and Life on Earth 11

2. Evidences for the Big Bang 12

A. Receding Galaxies and the Redshift 12

B. Hubble's Law of Uniform Expansion 14

C. The First and Second Laws of Thermodynamics 15

D. Inferences from Einstein's Theory of Relativity 18

E. Nucleosynthesis of Hydrogen, Helium, Deuterium, and Heavier Elements 20

F. The Cosmic Microwave Background 21

G. The Dark Sky at Night 22

3. Scientific Cosmological Agnosticism 23

TWO Humanistic Naturalism 29

1. Family Traits of Humanistic Naturalism 30

A. Nature as All Existence $\quad 30$

B. Nature as Purposeless 31

C. Nature as Infinite, Eternal, and Necessary 32

D. Nature Causes Everything 34

E. Scientific Method Alone 36

F. Humanism 40

2. How Scientific Is Humanistic Naturalism? 41

A. Humanistic Values and Scientific Method 41

B. Naturalistic Metaphysics and Scientific Method 43

i. Direct Observation 46

ii. Inductive Inference 49 
iii. Hypothesis Formation and Testing

a. The Hypotheses of "Creation Science" 53

b. Hypothetical Cosmological Entities and Processes

c. Naturalistic Metaphysical Hypotheses

THREE Steady State and Plasma Cosmologies $\quad 61$

1. Steady State Cosmology 61

2. Critique of Steady State Cosmology 62

A. No Observational Evidence 62

B. The Dark Sky, Microwave Background, Redshift, and Hubble Expansion 63

C. The First Law of Thermodynamics 63

D. Antimatter 64

E. Verifying Infinity 65

3. Plasma Cosmology and Eric Lerner's Critique of the Big Bang 66

$\begin{array}{ll}\text { A. Large-Scale Structures } & 67\end{array}$

B. Dark Matter and the Galaxies $\quad 68$

C. Cosmic Heterogeneity 72

D. Homogeneity and the Microwave Background 73

E. The Hubble Expansion and the Infinite Universe 74

4. Critique of Plasma Cosmology 78

A. A Universe Infinite in Space and Time 78

B. Hydrogen and An Infinitely Old Universe $\quad 80$

C. The Vastness of the Universe $\quad 82$

D. Mini-Bangs and the Age of the Universe 83

E. Electromagnetism and the Age of the Universe 85

F. Background Radiation $\quad 85$

G. The Smoothness of the Universe 85

FOUR Antecedent Universe Cosmologies $\quad 89$

1. Gamow's Infinite Squeeze/Bang/Rebound Universe 90

2. Critique of Gamow's Cosmology 90

A. Science and an Infinite Past 91

B. Gravity and Mass/Energy in the Squeeze Era 92

3. Oscillation Cosmology 93

A. Singularities $\quad 94$

B. Quantum Effects and Singularities 96

i. Quantum Indefiniteness 97

ii. Quantum Discreteness 98

4. Critique of Oscillation Cosmology 104

A. An Infinite Number of Closed Universes 104

B. Singularities vs. Finite Size Maximal Compression States 107 
i. Rebounds from Singularities?

ii. Big Bounces Without Singularities

C. Singularities and Universal Physical Causation $\quad 112$

D. Quantum Effects Near Singularities

E. Oscillationism and Thermodynamics

i. Entropy Can't Apply to the Universe as a Whole

ii. Entropy Can Apply to the Universe as a Whole

FIVE Big Fizz and Big Divide Quantum Cosmologies

1. Big Fizz Quantum Cosmology

A. Mother Spacetime

B. The Physical Vacuum and Pure Energy

C. Forever Blowing Bubbles

D. Spontaneous Fluctuations

2. Big Divide Many Worlds Cosmology

A. Schrödinger's Cat 130

B. Schrödinger's Cat in Many Worlds

3. Critique of World-Ensemble Cosmologies

A. Lack of Empirical Foundations and Meaning 132

B. Possibility = Actuality, and World-Ensembles

C. You and I in Many Worlds

SIX Quantum Observership Cosmology

1. Observers Create the Universe

2. Critique of Quantum Observership

A. Incompatibility With Cosmic and Biological Evolution 143

B. Idealism vs. Realism

i. Critical Realism and Quantum/Relativity Matter $\quad 147$

ii. Observership and Causation

iii. Ambiguities Involving "Observer" and "Measurement"

SEVEN Big Accident Quantum Cosmology

1. The Universe as a Big Accident

2. Critique of Big Accident Quantum Cosmology 164

A. Perfect Symmetry and Zero Energy 165

i. We Live in an Open Universe 165

ii. Matter Prevails over Antimatter 166

iii. The Bang Overpowers Gravity 168

B. Quantum Natural Laws Operating in Nothingness $\quad 170$

i. The Incoherence of Something in Nothing $\quad 170$

ii. Laws Are Only Formal Causes $\quad 171$

C. Total Abandonment of Causation 172 
i. Necessary but Not Sufficient Causal Conditions $\quad 172$

ii. Freedom Has Necessary Conditions 173

iii. Applying Causation to World-Origins 174

D. No Contingency Without Causation

EIGHT Atheistic Anthropic Cosmology 179

1. The Anthropic Principle and Cosmic Purpose Without God 179

2. The Weak and Strong Anthropic Principles 182

3. Critique of Infinite World-Ensemble Teleology 185

A. Non-Empirical Status $\quad 185$

B. The Principle of Plenitude 186

C. Infinity = All Possibilities 191

i. Infinity Is Not Infinite Diversity 192

ii. An Agent of Diversification Is Needed 193

iii. Infinite Possibilities Are Not All Possibilities $\quad 194$

iv. Infinity Would Not “Use Up" Lifeless Worlds 195

v. Actualizing All Possibilities Is Incoherent 196

D. Infinitely Many Life-Sustaining Universes 197

E. Infinite Time and the Inverse Gambler's Fallacy 199

F. Infinite Space and the Inverse Gambler's Fallacy 200

G. Faith vs. Reason 201

NINE The Final Anthropic Principle 203

1.The Omega Point as the Purpose of the Universe 203

2. Critique of the Final Anthropic Principle 204

A. Unfounded Assumptions 205

B. The Meaning and Value of Human Life 208

i. Human Existence as Merely a Means to Something Beyond 209

ii. Enduring Grand Objectives 210

iii. Human Insignificance in the

iv. The Intrinsic Worth of Human Existence 212

v. The Meaning and Value of Infinitely
Prolonged Existence

TEN Concepts of God's Nature and Existence 221

1.Two Concepts of God's Nature: Classical and Process Theology 221

A. Infinite in Being and Perfection 224

B. A Most Pure Spirit, Invisible, Without Body 228

C. Immense 230

D. Without...Parts 231

E. Without...Passions 231 
F. Immutable...Eternal 234

G. Almighty 235

2. Conceiving of God's Existence 236

A. Ordinary Existence 236

B. Necessary and Contingent Existence 241

3. Critique of Process Theology 242

A. God's Influencing and Being Influenced by the World 242

B. Our Freedom and God's Self-Limitation 253

C. How Process Theology Can Affirm Creation Ex Nihilo

i. A New Framework for Understanding

Creation Ex Nihilo

ii. Elements of Superspacetime in Process Thought 265

iii. Process Objections to Creation Ex Nihilo 267

ELEVEN The Biopic Teleological Argument 275

1. God's Purpose for the Universe and Cosmic Teleology 275

A. Extraordinary Cosmic Coincidences that Favor Life $\quad 277$

i. Matter/Antimatter Asymmetry 278

ii. A Weaker or Stronger Force of Gravity 279

iii. More or Less Mass/Energy 279

iv. The Size and Age of the Universe 279

v. Variations in the Electromagnetic Force 280

vi. Alterations of the Strong Force in Atomic Nuclei 280

vii. Variations in the Weak Force Controlling

Nuclear Decay

viii. Different Spatial Dimensions 281

ix. Additional Fine-Tuned Features 281

B. Inadequate Non-Theistic Explanations 282

i. Infinitely Many Worlds 282

ii. The Principle of Plenitude 284

iii. Nothingness 286

C. Probabilities Favor Divinity 287

Conclusion: God Ordered Our World 290

2. Critique and Defense of the Biopic Teleological Argument 291

A. Natural Creation of Order 291

B. The Insignificance of Life in a Vast Universe 292

C. The Big Mess: Evil and the Religious Ambiguity

of Order in Nature

i. Solutions that Don't Work 298

ii. A Process Theodicy that Works 299

a. The Free Will Defense 299

b. The Soul-Making Defense 302 
c. The Utility of Law and Order

d. The Conflict of Good with Good

TWELVE Theism and Cosmic Contingency 311

1. A Cosmological Argument from Contingency 312

A. Naturalistic Metaphysical Options $\quad 312$

B. Contingent Parts and Wholes $\quad 314$

C. No Necessary Parts of the Universe 319

D. Conclusion: The Dependence of the Universe on God 323

2. Critique and Defense of the Cosmological Argument from Contingency

A. The Universe Needs No God 323

i. Creating and Sustaining $\quad 326$

ii. Influencing and Saving $\quad 329$

B. Contingent Wholes Do Not Imply Necessary Causes 332

C. "Cause" Cannot Apply to the Universe as a Whole 335

D. God Also Must Have Had a Cause 337

E. Atheism Is Simpler than Theism 339

F. There Is no Universe as a Whole 342

G. Transcendent Reality Is Unknowable 345

$\begin{array}{ll}\text { Notes } & 347\end{array}$

$\begin{array}{ll}\text { Bibliography } & 379\end{array}$

$\begin{array}{ll}\text { About the Author } & 399\end{array}$

$\begin{array}{ll}\text { Index } & 401\end{array}$ 


\section{EDITORIAL FOREWORD}

The appearance of Rem B. Edwards's What Caused the Big Bang? marks the introduction of the first title in the Philosophy and Religion (PAR) special series. I cannot imagine a better way to introduce the special series to the academic world than to do so through the thought of a frequently cited scholar. This is PAR's first book, Edwards's sixteenth.

Edwards's erudition is everywhere in evidence as he devours the pages of Big Bang literature, separating fact from fancy, the examined from the unexamined. Socrates would recognize his sting as belonging to the most energetic of gadflies, unrelenting, pestering those who would readily ascribe the origin of the universe to anything less than disciplined reason requires. What caused the Big Bang? Now that the 15 billion-year-old cosmic dust has settled, several likely explanations emerge from the cosmic broth. But not all explanations are proven equal, as Edwards amply demonstrates: Steady State and Plasma Cosmologies; Antecedent Universe Cosmologies; Big Fizz and Big Divide Quantum Cosmologies; Quantum Observership Cosmology; Big Accident Quantum Cosmology; Atheistic Anthropic Cosmology; the Final Anthropic Principle-each view contains fatal flaws.

Edwards's thesis that God caused the Big Bang follows a detailed deconstruction of alternate models showing their weakness: where and how they commit fallacies. The burden of proof now falls squarely on the shoulders of those who do not accept the claim that God caused the Big Bang. Critics must point to the deficiencies in Edwards's argument and defend the superiority of their own view. This is a hard sell, given the breadth and depth of his work. But if God created the universe, what is our place in it? Who is God, why did God create, is God responsible for the suffering of innocent victims, and since the universe is contingent, does God sustain creation? Like all good philosophy, Edwards's answer to questions raises more questions!

In my own work on death and immortality, the mysterious nature of the nothing has long beckoned forth, inviting me to visit the nurturing intelligibilities it incloses. In discussions on death and dying, I find useful the distinction between the absence of something and the removal of ground in which the possibility of this absence arises. For instance, is death the absence of life or is it the removal of the possibility in which the possibility of absence arises? The simple answer is that it is both. The complex answer is that one distinction (ontological) raises the question of what death might be like to the dead (if post mortem states exist), while the other (epistemic) addresses the ordinary-language view of death as absence of life. The investigation into the ontological character of death (death as such), then is conducted from the perspective of the nothing as reversal in the possibility of temporal existence. Death is a return to the conditions that existed before the Big Bang. In part, my thesis depends on the existence of a state in the likeness of the nothing. Edwards's What Caused 
the Big Bang? provides solid evidence and confirms my own belief that God is at work in this domain.

If God caused the Big Bang, then, the universe had a beginning. It might not have had a beginning in time (the universe could be eternal), but it must have had a beginning in the order of existence (thereby providing an answer to the question, "Why is there something rather than nothing?"). If matter has a beginning, science cannot reach that far. The laws of the universe only become applicable at Planck Time and Planck Space or length; at $10^{-43 r d}$ of a second, the size of the universe was $10^{-33 r d}$ centimeter in diameter (see pp. 98-99 of this volume). This is as close to the moment of creation as science can get. So how can the Big Bang have a cause? Philosophy and/or religion take over at that point. Edwards's inquiry reveals that the gap separating the before and the after of existence (beyond scientific measurement) is not nothing at all since it is pregnant with the divine laws and patterns of existence. How else would the universe know to open the first act of existence in a scene of well-orchestrated expansion and contraction? Planets could not have formed in the absence of laws and patterns. The existence of the law implies structure. And structure points beyond contingency to the existence of a Necessary Being-or God at work in the ex nihilo.

Edwards's book is powerful and timely. His cogent analysis of quantum physics provides at least one indubitable truth that cannot be deconstructed-God exists! The current crisis in Ethics is due to the excesses of relativism. Once we accepted Hume's invitation to skepticism, Heidegger's critique of the Absolute, Nietzsche's death-of-God movement, and the genetic secularization of our species, nothing special was left to unite us. We found ourselves doing moral theory in the absence of a unified ethical vision of our common origin, nature, and destiny. Edwards's book provides the ontological grounding required for a fresh start. It should be required reading, not only where physics is taught, but whenever Philosophy and Religion matter.

Kenneth A. Bryson

Editor, Philosophy and Religion University College of Cape Breton Sydney, Nova Scotia, Canada

January 2001 


\section{PREFACE}

In 1988, Stephen W. Hawking wrote,

Up to now, most scientists have been too occupied with the development of new theories that describe what the universe is to ask the question why? On the other hand, the people whose business it is to ask why, the philosophers, have not been able to keep up with the advance of scientific theories.'

My professional training as a philosopher has contributed immensely to my preparation for writing this book; and I have done my best to try to understand those scientific theories which have a direct bearing on my central question: What caused the Big Bang? I hope that my inquiry brings together successfully both the what and the why of the origin of the universe. This topic has long fascinated me, and I have read and thought extensively about it. My considerable reading about the Big Bang, my background in Process Philosophy, with its emphasis on uniting philosophy and science, and my training, teaching, and writing in the philosophy of religion have all helped to prepare me for this enterprise.

Almost everyone is curious about the origin of the universe; and my intended audience is philosophers, theologians, scientists, and all inquisitive persons who wonder how and why it all began. I agree with George Smoot that there is a "deep public interest in understanding the origin of the universe and our place in it,"” so this book is written for the average literate person, not just for professionals. In places, however, the subject matter is difficult. To quote Hawking again:

...If we do discover a complete theory, it should in time be understandable in broad principle by everyone, not just a few scientists. Then we shall all, philosophers, scientists, and just ordinary people, be able to take part in the discussion of why it is that we and the universe exist. If we find the answer to that, it would be the ultimate triumph of human reason-for then we would know the mind of God. ${ }^{3}$

With Smoot and Hawking, I share this ultimate goal and address this broad audience. My contribution will be to ask and try to answer philosophical questions of scientists, who are usually at least as naive about philosophy as philosophers are about science. I also want to show ordinary people what the best scientific minds are saying about the origin of the universe, and how to think critically and philosophically about their theories. In thinking about the ultimate origin of the universe, we are in the borderlands between science, philosophy, and religion. 
I will try to present the major answers that contemporary scientific cosmologists are giving to: What caused the Big Bang? For many persons, this question has a simple and direct answer: God did it. When the Belgian astronomer/priest George Lemaitre first understood the evidence for the Big Bang, he was probably convinced personally that science had discovered the moment when God created the world; ${ }^{4}$ but he tended to keep his views on how religion relates to astronomy to himself. In a 1951 address, Pope Pius XII claimed that "True science discovers God in an ever-increasing degree-as though God were waiting behind every door opened by science.... Science has provided proof of the beginning of time....Hence, creation took place in time. Therefore, there is a Creator; therefore, God exists."5

Those who believe that things are so easy will be surprised to learn that most contemporary scientific cosmologists are doing their best to avoid the hypothesis that God created or caused the Big Bang. Most presuppose a Naturalistic metaphysics, according to which the universe has been around in some form from eternity with no conceivable dependence on Deity. Many scientists believe that the Big Bang, which initiated our cosmic epoch, was caused by an antecedently existing universe, not by God's creative activity. Some scientific cosmologists try to avoid God by maintaining that the Big Bang had no cause at all. Coming chapters will survey both secular and religious accounts of cosmic origins and evaluate them on their own merits.

Chapter One of this book reviews the overwhelming evidence that convinces most scientists today that our universe began with a Big Bang somewhere between eight and twenty billion years ago; and it charts the course of the evolution of the universe from an initiating Big Bang to where we are today. It explores the possibility that science cannot answer the question of ultimate origins because the topic lies beyond the proper bounds of legitimate science. Good science involves both theory and empirical confirmation, but many contemporary scientific cosmologists are producing only content-less theories about what caused the Big Bang. Scientific Cosmological Agnostics deny that our question is properly scientific and indicate that the pseudoscientific theories which try to answer it cannot be verified, even indirectly. Only experience can separate actualities from abstruse possibilities, reality from wild speculation; yet we have no experience of worlds creating other worlds.

In Chapter Two, Naturalistic Humanistic theories of reality (metaphysics), of knowledge (epistemology), and of human origins (humanistic anthropology) and well-being (ethics and axiology) are introduced, subjected to thorough philosophical analysis and criticism, and shown definitively to be untenable. All the non-theistic answers to: What caused the Big Bang? examined in Chapters Three through Nine are deeply embedded within an indefensible Naturalistic Humanistic philosophical outlook.

Chapter Three explores significant challenges to the idea that our universe originated in a Big Bang. Steady State Cosmology, developed by Fred Hoyle 
and his associates in the 1940s and 1950s, affirms that the universe is uncreated and that it maintains its present general appearance from eternity; so there was no Big Bang. The Hubble expansion of the universe results from the continuous creation of hydrogen atoms out of nothing by matter. New atoms fill in the blanks left by the Hubble expansion of the universe. Steady State Cosmology is not alone in affirming that the physical universe is spatially and temporally infinite. In The Big Bang Never Happened, ${ }^{6}$ Eric Lerner offers seemingly powerful objections to the evidence that convinces most scientists that the Big Bang really happened, and he presents his own Plasma Cosmology which, when all is said and done, relies upon a local Mini-Bang to explain what is happening in the finite part of the infinite universe that is observable to us. Decisive objections to his position are developed.

In Chapter Four, two versions of the theory that our universe was created by the collapse of an antecedently existing universe are discussed. George Gamow thought that a shrinking universe infinitely preceded our own in a time before our time and finally collapsed in a Big Crunch. It then rebounded, and our resulting universe will expand forever. We exist in a life-supporting phase of the endless rebound period. Where Gamow's Cosmology postulates only one contraction, one crunch, one Bang, and one rebound, Oscillation Cosmology conjures up an infinite number of antecedent universes, each of which began in a Big Bang, expanded to a maximal state, recontracted, then renewed the whole process with another Big Bang. Oscillationists propose that an influx of energy from an antecedently existing universe caused the Big Bang and our resulting cosmos, but the position is fatally flawed, as this chapter shows.

Quantum theory has powerfully influenced cosmological speculation since the early 1980s. Chapters Five through Eight explore a variety of Quantum Cosmologies, each of which has its own peculiar answer to the question of cosmic origins.

Big Fizz Cosmology covered in Chapter Five says that our Big Bang was created when energy bubbles formed through spontaneous quantum fluctuations in the womb of an antecedently existing Superspacetime or Mother Spacetime. Infinitely many bubbles form spontaneously to make infinitely many universes, which co-exist within Mother Spacetime. Our bubble inflated fifteen billion or so years ago, so here we are! Big Divide Cosmology says that every universe sub-divides itself into infinitely many universes at every turn of events, so we are here for a brief moment within a universe that looks like it began in a Big Bang, but it really began only a fraction of a second ago when an antecedent universe sub-divided to actualize all possibilities. But these cosmologies are utterly implausible, as demonstrated.

Quantum Observership examined in Chapter Six emphasizes the important role that some interpreters of quantum mechanics assign to scientific observers, measurers, and experimenters. It maintains that the indefinite and indeterminate domain of quantum events takes on definiteness and determinateness only when 
observers view it. Evidence for the Big Bang exists only as human observers find it-and thereby create it. So what created the Big Bang? We did! (But we didn't, as the concluding critique proves.)

Big Accident Cosmology contends, as explained in Chapter Seven, that the question of what caused the Big Bang presupposes something that supposedly is not true, namely that everything which comes into being has a cause. Quantum physics denies this, we are told, and discloses that our universe originated out of nothing, was caused by nothing, exists for no purpose, and is nothing. Nothing caused the Big Bang. It is so easy for nothing to cause nothing! Just why our universe did not originate this way is carefully explained.

Chapter Eight considers Atheistic Anthropic Cosmology. Many recent scientific cosmologists note that our universe is exceptionally fine-tuned for the creation of life, including intelligent forms of life. Tiny changes in any of the initial conditions, constants, and laws of nature would have resulted in a universe inhospitable to life. For every successful way of creating a life-supporting universe, there are infinitely many futile ways to get it wrong. Lifeless universes are infinitely probable, and life-supporting universes are infinitely improbable. Why, then, do we live in a life-supporting universe? The Anthropic Principle says that we live in a life-supporting universe because we are here, that is, because if the universe were not life-supporting, we would not be here to ask questions about it. Even atheists do not deny the remarkable life-supporting design of our universe, but they think that they can account for this without having to appeal to God. Atheistic Anthropic Cosmology explains that if infinitely many worlds exist, as many Quantum Cosmologies profess, then universes as rare as our own will just happen occasionally. Given an infinite number of shoes, one will fit now and then by pure chance. The metaphysical Principle of Plenitude, that all possibilities must be actual somewhere, guarantees the existence of an infinite number of universes. For Atheistic Quantum Cosmologists, the Principle of Plenitude is the ultimate cause of our Big Bang plus infinitely many other universes, very few of which life-sustaining. The innumerable flaws of Atheistic Anthropic Cosmology are spelled out in detail.

Chapter Nine deals with the bizarre claims made by the Final Anthropic Principle, according to which our universe and an infinite number of others will ultimately coalesce into a single omniscient and omnipotent Omega Point that will be God. God does not now exist and did not create the world; but the world, which began without God, now exists and will ultimately create God. Human life is meaningful because through our android descendants we can contribute to the development of the Omega Point by traveling in space and ultimately inhabiting our entire universe. The position borders on madness, as explained!

These atheistic theories and a few theistic accounts of what caused the Big Bang are explained and critically examined in significant depth in chapters to follow. When considered critically and seriously, much of the atheistic cosmological speculation being done by today's astronomers, astrophysicists, and 
other scientists is quite outlandish, as the preceding paragraphs suggest. Once this is fully understood and appreciated, the door is open to reexamine the possibility that God caused the Big Bang. Still, some ways of conceiving of the nature of God and of God's relations with the world are much more intelligible than others, and much easier to relate to the universe disclosed to us in Big Bang Cosmology.

Two quite different concepts of God are examined in Chapter Ten. Classical Theism is committed to the absolute changelessness of God in every conceivable respect. Process Theism, by contrast, affirms that God is indeed changeless in certain desirable respects but is in process in other highly desirable respects. It is desirable both that God be changelessly good and that God's experiences change as God interacts with created worlds and their creatures as they come in to being in spacetime and history. A comprehensive but modified Process Theology best reconciles science and religion. Chapter Ten also discusses several senses in which God may be said to "exist" and develops and justifies several changes in Process Theism that seem desirable, upon examination, if it is to be rationally and religiously appealing.

Chapter Eleven presents a revitalized Biopic Teleological Argument for the existence of God, based upon massive evidence for the fine tuning of the universe for life, as disclosed by contemporary scientific cosmology. Note that when masculine pronouns are used occasionally in reference to God in this chapter and elsewhere, this is done merely from convention and for economy or convenience of expression; but it in no way implies that God is masculine in any intelligible or defensible sense.

Chapter Twelve further develops the case for Theism with a refurbished Cosmological Argument from Contingency for the existence of God, again based upon what contemporary physics and astrophysics have revealed about the radically contingent nature of physical reality.

To my knowledge, no existing book covers and critically examines philosophically all the major options for explaining the origin of the Big Bang. The astute debate between William L. Craig and Quentin Smith in their Theism, Atheism, and Big Bang Cosmology ${ }^{7}$ focuses almost exclusively on the Standard Model of the Big Bang, with its initial singularity, and on the quantum Big Accident option; but it neglects all the other theories of origin explored here. M. A. Corey's God and the New Cosmology: The Anthropic Design Argument ${ }^{8}$ deals mainly with the teleological but not in depth with the cosmological argument for God's existence. As endnotes for each following chapter will indicate, numerous books and articles examine and defend one particular theory or another. Yet, no previous book takes a hard philosophical look at all the basic options presented here while critically examining the Naturalistic assumptions that underlie the non-theistic scientific (or pseudoscientific) cosmologies covered in Chapters Three through Nine. Many cosmologists emphasize scientific 
data and theories. While not neglecting these, I also introduce relevant philosophical questions, analysis, and theories.

I wish to express special appreciation to The University of Tennessee for the Faculty Development Grant which it awarded to me to work on this project, and to my former Department Heads, George Brenkert and Kathy Bohstedt, for their substantial support for my efforts. Kenneth A. Bryson, editor of the Religion and Philosophy special series of the Value Inquiry Book Series, was immensely helpful in spotting defects that I was not able to see, but final responsibility for imperfections in the book rests with me. And many, many thanks to my wife Louise who managed to tolerate my existence while I was so deeply immersed in the project of figuring out the universe. 


\section{ACKNOWLEDGMENTS}

I thank the following publishers for their kind permission to reprint or paraphrase copyrighted materials, especially Barry Whitney, editor of Process Studies, which previously published my discussion of "How Process Theology Can Affirm Creation Ex Nihilo," 29:1 (Spring-Summer 2000), pp. 77-96 that appears here as a section of Chapter Ten. Short quotations and references in this volume should fall within the realm of "fair use," but for permission to use more detailed material, I thank the following:

Cambridge University Press: James Cornell, ed., Bubbles, Voids, and Bumps in Time: The New Cosmology, 1989.

Clarendon Press, a division of Oxford University Press: William L. Craig and Quentin Smith, Theism, Atheism, and Big Bang Cosmology, 1993.

Mind, an Oxford University Press publication: Ian Hacking, "The Inverse Gambler's Fallacy," 96 (1987), pp. 331-340.

Open Court Publishing Company: Charles Hartshorne, Creative Synthesis and Philosophic Method, 1970.

Oxford University Press: John D. Barrow and Frank J. Tipler, The Anthropic Principle, 1989.

Process and Faith: John B. Cobb, Jr., "Is God Creator Ex Nihilo?” Web site, July-August, 1999.

Prometheus Books: Kai Nielsen, Naturalism without Foundations, 1996; Victor J. Stenger, The Unconscious Quantum: Metaphysics in Modern Physics and Cosmology, 1995.

Random House, Alfred A. Knopf: Eric J. Lerner, The Big Bang Never Happened, 1991.

Random House, Bantam Dell Publishing Group: Stephen W. Hawking, A Brief History of Time, 1988, 1996.

Sky \& Telescope: Cheryl J. Beatty and Richard T. Fienberg, "Participatory Cosmology: The Big Bang Challenge" (March 1994), pp. 20-22; "Extrasolar Planet Seen Transiting Its Star" (February 2000), pp. 16-17; "The Great Attractor's Hidden Heart" (December 1999), p. 12; Robert Jastrow, "What Are the Chances for Life?" (June 1997), p. 63; Alan M. MacRobert, "Beyond the Big Bang" (March 1983), pp. 211-213; Sten Oldenwald, "Spacetime: The Final 
Frontier"(February 1996), pp 24-29; "The Primordial Soup: A Recipe for Life" (February 1998), p. 20; Joshua Roth and Joel R. Primack, "Cosmology: All Sewn Up or Coming Apart at the Seams" (January 1996), pp. 20-26; Gary H. Sanders and David Beckett, "LIGO: An Antenna Tuned to the Songs of Gravity" (October 2000), pp. 41-48.

Yale University Divinity School: Robert Jastrow, "Science and the Creation," in Creation (a special issue of Reflection), edited by Thomas Schattauer, 1980.

Writers House LLC: Stephen W. Hawking, A BriefHistory of Time, 1988, 1996.

Zygon, a Blackwell publication: Joel Friedman, "The Natural God: A God Even an Atheist Can Believe In" (September 1986), pp. 369-388; Fred W. Hallberg, "Barrow and Tipler's Anthropic Cosmological Principle" (June 1988), pp. 139-157; Frank J. Tipler, "The Omega Point as Eschaton: Answers to Pannenberg's Questions for Scientists"(June 1989), pp. 217-253; Patricia A. Williams, "Christianity and Evolutionary Ethics: Sketch Toward a Reconciliation" (June 1996), pp. 253-268. 